\title{
Deposition of $\beta$-SiC by a LPCVD Method and the Effect of the Crystallographic Orientation on Mechanical Properties
}

\author{
Daejong Kim* ${ }^{\dagger}$, Jongmin Lee***, Weon-Ju Kim*, Soon Gil Yoon**, and Ji Yeon Park* \\ *Nuclear Materials Division, Korea Atomic Energy Research Institute, Daejeon 305-353, Korea \\ **Department of Materials Engineering, College of Engineering, Chungnam National University, Daejeon 305-764, Korea \\ (Received December 5, 2012; Revised January 18, 2013; Accepted January 21, 2013)
}

\section{저압 화학기상증착법을 이용한 $\beta-\mathrm{SiC}$ 의 증착 및 결정 성장 방위에 따른 기계적 특성 변화}

\author{
김대종*† $*$ 이종민 $* * * *$ 김원주* · 윤순길** · 박지연* \\ *한국원자력연구원 원자력재료개발부 \\ ** 충남대학교 재료공학과
}

(2012년 12월 5일 접수 ; 2013년 1월 18일 수정 ; 2013년 1월 21일 채택)

\begin{abstract}
$\beta$-SiC was deposited onto a graphite substrate by a LPCVD method and the effect of the crystallographic orientation on mechanical properties of the deposited $\mathrm{SiC}$ was investigated. The deposition was performed at $1300^{\circ} \mathrm{C}$ in a cylindrical hot-wall LPCVD system by varying the deposition pressure and total flow rate. The texture and crystallographic orientation of the SiC were evaluated by XRD. The deposition rate increased linearly with the gas flow rate from $800 \mathrm{sccm}$ to $1600 \mathrm{sccm}$. It also increased with the pressure but became saturated above a total pressure of $3.3 \mathrm{kPa}$. In the range of $3.3-10 \mathrm{kPa}$, the preferred orientation changed from the (220) and (311) planes to the (111) plane. The hardness and elastic modulus showed maximum values when the SiC had the (111) preferred orientation, though it gradually decreased upon a change to the (220) and (311) preferred orientations.
\end{abstract}

Key words : Silicon carbide, CVD, Crystallographic orientation, Nanoindentation, Hardness

\section{1. 서 론}

화학기상증착법(chemical vapor deposition, CVD)에 의해 제조된 탄화규소 $(\mathrm{SiC})$ 는 우수한 고온기계적 특성 및, 산 화저항성을 가질 뿐만 아니라, 중성자 흡수단면적이 매우 작고(열중성자 흡수계수 $=0.09 \mathrm{barns}$ ), 조사에 의한 기계 적 강도의 저하가 거의 없으며, 높은 조사량에도 부피변 화가 거의 없기 때문에 원자력 분야에서 다양한 활용이 이루어질 것으로 보인다. ${ }^{1)}$ 이러한 우수한 고온 및 중성자 특성으로 인하여, $\mathrm{SiC}$ 는 원자로의 노심재료(reactor core materials)로 사용되기에 적합하며, 4세대 원전 중 하나인 초고온가스로의 TRISO (tristructural-isotropic) 피복입자 핵 연료의 $\mathrm{SiC}$ 피복층, 제어봉 외피 소재로 $\mathrm{SiC}_{\mathrm{f}} / \mathrm{SiC}$ 복합체 가 고려 되고 있다. ${ }^{2,3)}$ 특히, 미국의 TMI (three mile island) 및 일본 후쿠시마 원전 사고 이후, 가압형 경수로

\footnotetext{
${ }^{\dagger}$ Corresponding author : Daejong Kim

E-mail : dkim@kaeri.re.kr

Tel : +82-42-868-4559 Fax : +82-42-862-8549
}

의 핵연료 피복관으로 사용되는 금속 피복관의 고온 산 화에 의한 수소발생 문제가 제기되며, 대체 재료를 개발 하기 위한 연구가 활발히 이루어 지고 있다. 현재 가동중 인 가압형 경수로의 핵연료 피복관은 Zircoloy-4, Zirlo 등 의 지르코늄 합금이 사용되어 왔으나, LOCA (loss-ofcoolant accident)와 같은 중대사고(severe accident)시 냉각 재의 유실로 인하여 핵연료 피복관의 온도가 상승되고, 이로 인하여 고온에서 지르코늄 합금과 냉각재의 산화반 응에 의해 대량의 수소가 발생하기 때문에 수소폭발의 위 험성이 매우 크다. ${ }^{4}$ 따라서, 원자로의 비정상 운전시 냉 각재와의 반응에 의한 수소발생량이 매우 낮고, 고온 기 계적 특성이 우수한 $\mathrm{SiC}_{\mathrm{f}} \mathrm{SiC}$ 복합체가 지르코늄 합금 핵 연료 피복관의 대체 재료로 활용될 수 있을 것으로 기대 되고 있다. ${ }^{5)}$

삼중층 형태의 세라믹 복합체 핵연료 피복관은 3 개 층 으로 구성되어 있으며, 핵연료의 핵분열로부터 발생하는 핵분열생성물이 냉각재로 확산하는 것을 방지하는 기능 을 하는 $\mathrm{SiC}$ 가스기밀층, 핵연료 피복관의 인성을 부여 
하는 $\mathrm{SiC}_{\mathrm{f}} / \mathrm{SiC}$ 복합체 중간층, 그리고 냉각재에 의한 $\mathrm{SiC}_{\mathrm{f}} f$ $\mathrm{SiC}$ 복합체의 부식을 막기 위한 $\mathrm{SiC}$ 내환경층으로 구성 되어 있다. 이 중 $\mathrm{SiC}$ 가스기밀층 및 내환경층은 중성자 조사에 의한 열적, 기계적 특성 저하를 줄이기 위해 고순 도의 우수한 화학정량을 가져야 하며, 높은 밀도, 균일한 증착층의 두께, 균질한 표면상태 등이 요구되고 있다. 특 히, $\mathrm{SiC}$ 층은 약 $15 \mathrm{MPa}$ 압력의 원자로 1 차측 냉각수에 의한 외압과 더불어 핵연료 압력관 내에 존재하는 핵연 료의 조사팽창에 의한 내압을 견뎌야 하는 구조재료로써 의 역할을 하기 때문에, 세라믹 핵연료 피복관의 구성요 소인 $\mathrm{SiC}$ 층의 기계적 특성과 이에 영향을 미치는 미세 구조 및 결정 방위 등이 매우 중요한 요소가 된다.

고순도의 우수한 화학정량을 가지는 고밀도 $\mathrm{SiC}$ 층을 제조하기 위해서 화학기상증착(chemical vapor deposition, $\mathrm{CVD}$ )법이 널리 이용되고 있으며, $\mathrm{CVD}$ 를 이용한 $\mathrm{SiC}$ 증 착 및 증착 특성, 이에 따른 열적, 기계적 특성 등에 관 한 많은 연구들이 수행 되어져 왔다. ${ }^{6-8)} \mathrm{SiC}$ 증착 방법은 MTS (methyltrichlorosilane) 또는 DMS (dimethyldichlorosilane)를 precursor로 사용하는 CVD법이 대표적이며, 고 순도의 우수한 화학정량을 가지는 $\beta-\mathrm{SiC}$ 상이 생성되는 것으로 알려져 있다. ${ }^{910)} \mathrm{SiC}$ 증착은 증착온도, 원료기체 및 희석기체의 분압, 증착압력, 기체 유량 등에 따라 증 착율 및 증착층의 특성이 변화될 수 있으며, ${ }^{10-12)}$ 증착 위 치에 따른 반응물질의 고갈 (reactant depletion)에 의한 증 착특성 변화도 관찰이 되고 있다. ${ }^{13)}$ 특히, $\mathrm{CVD}$ 법에 의 해 제조된 $\mathrm{SiC}$ 는 증착 조건에 따라 결정 방위가 쉽게 변 할 수 있으며, 이에 따른 미세구조 및 기계적 성질의 이 방성이 보고되고 있다. ${ }^{14,15)}$

따라서, 본 연구에서는 세라믹 복합체 핵연료 피복관의 $\mathrm{SiC}$ 가스기밀층 및 내환경층의 제조를 위한 연구의 일환 으로 $\mathrm{CVD}$ 방법에 의한 고순도 $\mathrm{SiC}$ 증착에 관한 연구를 수행하였으며, 증착기체의 유속 및 증착압력에 따른 $\mathrm{SiC}$ 증착층의 특성 변화와 결정방위에 따른 경도 및 탄성계
수의 변화를 평가하였다.

\section{2. 실험방법}

실린더 형태의 hot-wall CVD 수평로를 이용하여 저압 화학기상증착(low pressure chemical vapor deposition, $\mathrm{LPCVD}$ )법에 의해 $\mathrm{SiC}$ 를 증착하였다. Fig. 1 은 증착 실험 에 사용된 LPCVD의 개념도를 보여 주고 있다.

$\mathrm{SiC}$ 증착용 기판으로 등방성 고순도 흑연인 IG-110 (열 팽창계수 $=4.5 \times 10^{-6} / \mathrm{K}$ )을 사용하였으며, 증착용 흑연 기 판은 직경 $10 \mathrm{~mm}$, 두께 $1 \mathrm{~mm}$ 의 쿠폰 형태로 $7^{0}$ 경사를 가지는 경사판 위에 올려 두고 증착 시험을 수행하였다. 증착 원료물질은 $\mathrm{CH}_{3} \mathrm{SiCl}_{3}$ (methyltrichlorosilane, MTS), 운반 및 희석 기체로는 고순도 $\mathrm{H}_{2}(99.999 \%)$ 를 이용하였 다. 액체상인 MTS는 냉각장치(chiller)에서 $0^{\circ} \mathrm{C}$ 로 유지되 었으며, 운반 기체인 $\mathrm{H}_{2}$ 가 MTS로 통과함으로써 일정량 의 MTS가 반응기로 공급되었고, 원료 기체에 대한 희석 기체의 비 $\left(\alpha=\mathrm{P}_{\mathrm{H} 2} / \mathrm{P}_{\mathrm{MTS}}\right)$ 가 5 가 되도록 조절 하였다. 증착 온 도는 $1300^{\circ} \mathrm{C}$ 로 고정을 하였으며, $\mathrm{SiC}$ 의 증착율 및 미세구 조 변화를 살펴보기 위해 기체의 총유량은 800-1600 sccm, 증착 압력은 $1.3-10 \mathrm{kPa}$ 로 변화시켰다. 증착된 $\mathrm{SiC}$ 층의 결정구조 및 우선성장방위는 $\mathrm{XRD}$ 를 이용하여 분석하였 으며, 증착층의 결정방위에 따른 기계적 특성 변화를 평 가하기 위해 나노인덴테이션 분석을 수행하였다. 나노인 덴테이션 측정을 위한 $\mathrm{SiC}$ 샘플은 $1300^{\circ} \mathrm{C}, 1200 \mathrm{sccm}$ 기 체 유량에서 5 시간 동안 증착되었으며, 증착 압력이 3.3$10 \mathrm{kPa}$ 인 조건에서 증착된 결정의 우선 배향성이 다른 $\mathrm{SiC}$ 를 이용하였다. 증착된 $\mathrm{SiC}$ 층을 $1 \mu \mathrm{m}$ 까지 연마를 한 후, 약 20 회 이상 측정하였다. Fused silica $\left(\mathrm{SiO}_{2}\right)$ 표준 샘 플을 이용하여 나노인덴테이션 장비를 교정한 후, Berkovich 나노인덴터 팁을 이용하여 최대 하중을 $80 \mathrm{mN}$ 로 설정하 여 경도 (hardness) 및 탄성계수 (elastic modulus)을 측정하 였으며, $\mathrm{SiC}$ 의 포아송 비는 0.21 로 취하였다.

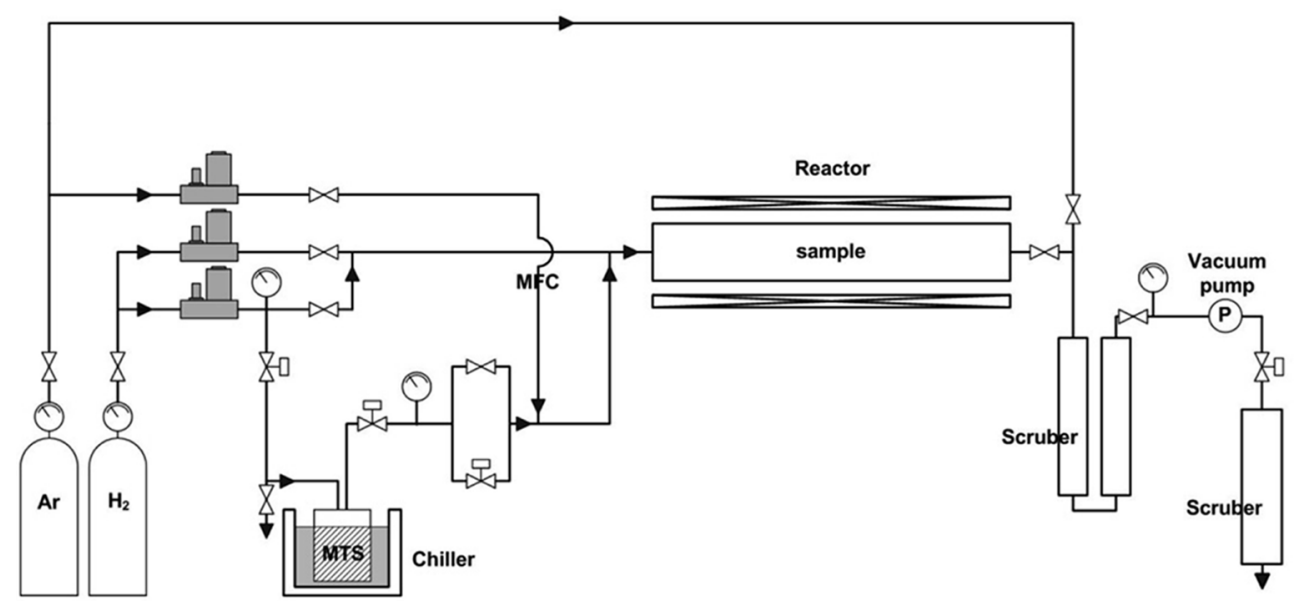

Fig. 1. Schematic diagram of a LPCVD system for $\beta$-SiC deposition. 


\section{3. 결과 및 고찰}

\section{1. 기체유량 및 증착 압력에 따른 증착율 및 미세구조 변화}

Fig. 2 는 $1300^{\circ} \mathrm{C}, 3.3 \mathrm{kPa}$ 의 증착 압력에서 기체의 총유 량의 변화에 따른 $\mathrm{SiC}$ 의 증착율의 변화를 보여 주고 있 다. 기체의 총유량이 증가함에 따라, $\mathrm{SiC}$ 의 증착율은 선 형적으로 증가 한다. 일반적으로 $1000^{\circ} \mathrm{C}$ 이하의 온도에서 는 기체 유량이 적을 경우 물질전달(mass transfer)에 의해 증착율이 결정 되며, 유량이 증가할수록 화학반응(chemical reaction)이 율속 반응이 된다. ${ }^{11)}$ 화학반응이 율속 반응이 되는 영역에 있을 경우 기체 확산층을 통한 반응 기체의 확산이 원활하기 때문에 기체의 유량은 증착율에 큰 영 향을 미치지 않는다. 그러나 온도가 높아짐에 따라 반응 속도가 빨라지며 기체 확산층이 넓어지게 되고, 이에 따 라 물질전달/화학반응 기구의 전이를 위한 임계 기체 유 량은 높은 값으로 이동하게 된다. $1300^{\circ} \mathrm{C}$ 의 증착 온도는 기체확산에 의한 물질전달 기구에 의해 증착율이 지배를 받는 구간으로, ${ }^{12)}$ 증착 표면에서의 화학 반응이 매우 빠 르기 때문에 넓은 기체 확산층이 형성된다. $1600 \mathrm{sccm}$ 이 하의 기체 유량에서는 완전한 물질 전달 반응에 의해 $\mathrm{SiC}$ 가 증착 되어 유량에 따른 증착율의 증가가 관찰 된 것

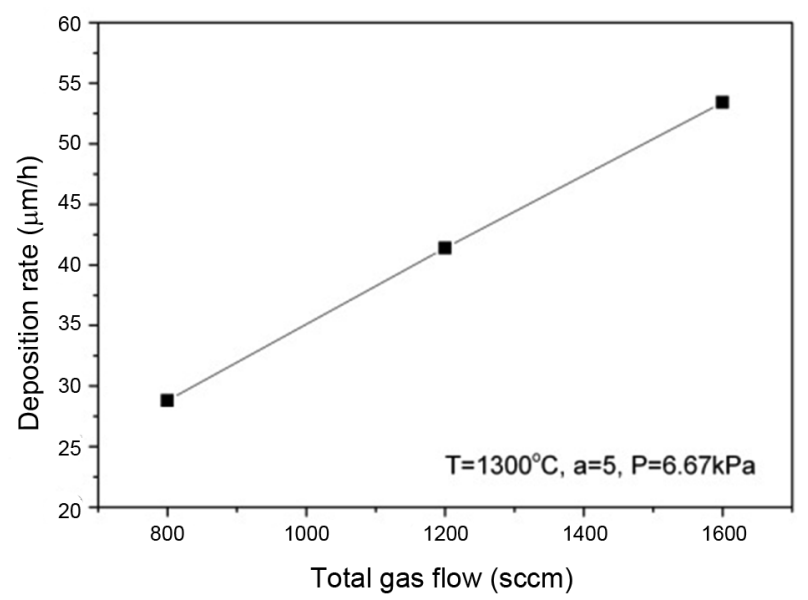

Fig. 2. Deposition rates of $\mathrm{SiC}$ as a function of total gas flow.

\section{으로 판단된다.}

Fig. 3은 기체의 총유량의 변화에 따른 $\mathrm{SiC}$ 의 표면 및 파단면의 미세구조를 보여 주고 있다. 모든 증착 조건에 서 $\mathrm{SiC}$ 는 거친 표면을 가지며 pebble 형태의 미세구조를 가지는 것으로 관찰되었고, $\mathrm{SiC}$ 층의 두께에 관계없이 치 밀한 구조를 띄고 있다.

Fig. 4는 $1300^{\circ} \mathrm{C}, 1200 \mathrm{sccm}$ 의 기체 유량에서 증착 압 력에 따른 $\mathrm{SiC}$ 증착율의 변화를 보여 주고 있다. 증착 압 력이 $3.3 \mathrm{kPa}$ 까지 높아짐에 따라 증착율이 증가하고 있으 나, 더 높은 압력에서는 증착율의 변화는 거의 관찰이 되 지 않는다. 앞서 설명한 바와 같이, $1200 \mathrm{sccm}$ 의 기체 유 량에서는 물질전달 기구에 의해 증착율이 결정이 되며, 증착 압력에 따른 $\mathrm{SiC}$ 증착 기구의 변화는 크지 않을 것 으로 판단이 된다. 그러나, 증착 압력이 매우 낮을 경우 식 (1)에서 볼 수 있는 바와 같이 증착 온도와 기체 유량 이 일정한 조건에서 증착층 표면에서 기체의 선속도(v)는 시스템 압력의 역수에 비례하게 되어, 급격하게 증가하게 된다. ${ }^{16)}$

$$
v=\frac{Q P_{0} T_{s}}{S P_{t o t} T_{0}}
$$

여기서, $\mathrm{Q}$ 는 기체유량, $\mathrm{P}_{0}$ 는 표준기압, $\mathrm{T}_{\mathrm{s}}$ 는 증착온도, $\mathrm{S}$ 는 증착반응로의 단면적, $\mathrm{P}_{\text {tot }}$ 은 반응로의 총압력, $\mathrm{T}_{0}$ 는 $298 \mathrm{~K}$ 이다.

선속도가 매우 클 경우 증착 표면에서 반응 기체의 잔 류 시간(1/v)이 줄어들며, 분해 반응이 충분히 일어나지 못하기 때문에 증착율이 감소될 수 있다. Loumage 등의 $\mathrm{SiC}$ 증착 연구에 의하면, ${ }^{11)} 900^{\circ} \mathrm{C}$ 이하의 온도에서는 약 $30 \mathrm{kPa}$ 의 높은 증착 압력까지 선형적으로 비례하여 증가 하는 거동을 보인다. 그러나, $900^{\circ} \mathrm{C}$ 이상의 온도에서는 약 $3 \mathrm{kPa}$ 의 증착 압력 이상에서 증착율의 변화가 관찰되지 않거나, 오히려 감소하는 경향을 보이고 있음을 알 수 있 다. 반응 온도는 기체의 선속도에 큰 영향을 미치지 않기 때문에, ${ }^{17)} 1300^{\circ} \mathrm{C}$ 의 온도에서도, $1000^{\circ} \mathrm{C}$ 이하의 저온에서 관찰된 경향과 같은 거동을 보일 것으로 예측되며, 특히 $3.3 \mathrm{kPa}$ 이상의 압력에서는 선속도가 완만하게 감소를 하기

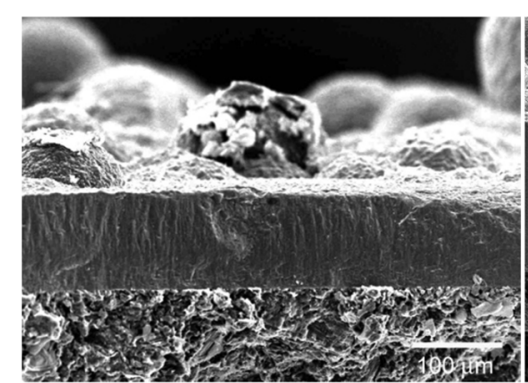

(a)

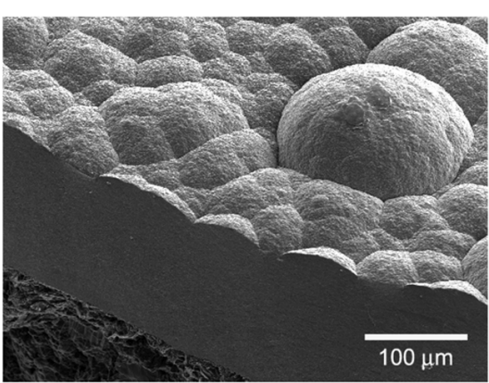

(b)

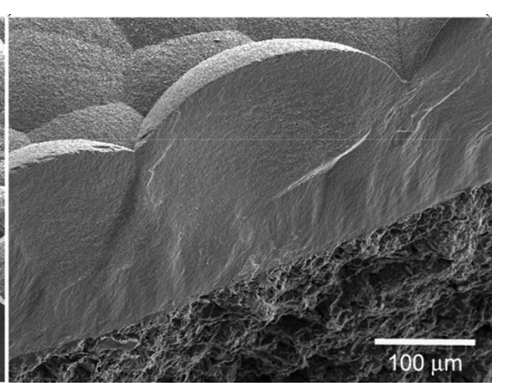

(c)

Fig. 3. Surface and fractured morphologies of $\mathrm{SiC}$ deposited at $1300^{\circ} \mathrm{C}$ under different total flow rate: (a) $800 \mathrm{sccm}$, (b) $1200 \mathrm{sccm}$, and (c) $1600 \mathrm{sccm}$. 
때문에, 증착율의 변화가 크지 않은 것으로 판단이 된다.

Fig. 5는 증착 압력에 따른 $\mathrm{SiC}$ 표면 미세구조의 변화 를 보여 주고 있다. 모든 증착 압력 조건에서 $\mathrm{SiC}$ 는 거시 적으로 Fig. 3과 같이 pebble 구조를 가지고 있다. 그러나, 고배율 사진에서 보는 바와 같이, $6.7 \mathrm{kPa}$ 증착 압력 이하 에서는 표면의 결정립이 미세한 angular 형태의 구조를 보 이고 있으나, $10 \mathrm{kPa}$ 에서는 우수한 결정성을 가지는 조대 한 입자의 strong facet 구조가 관찰되고 있다. 이러한 구 조의 변화는 증착 온도가 낮아지거나, 입력 기체비 $(\alpha)$ 값 의 증가 등에 의한 증착 기구의 변화로부터 발생하는 경 우가 대부분이며, ${ }^{12,18,19)}$ 본 연구에서는 압력이 증가함에 따라 hot-wall CVD 장치에서 반응물질의 고갈(reactant depletion)에 의해 기체 확산층이 넓어짐에 따라 시편 주 위에서 반응 물질의 국부적인 고갈이 발생했기 때문으로 판단이 된다. ${ }^{13)}$

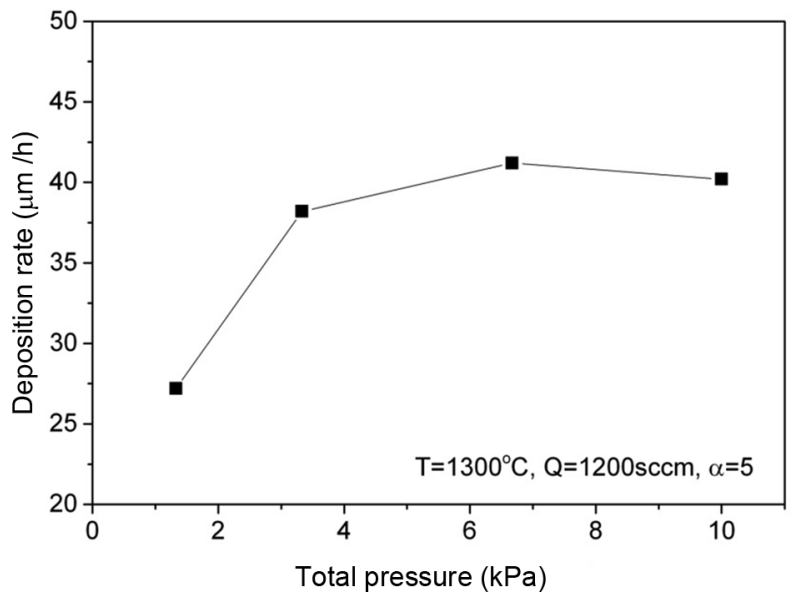

Fig. 4. Deposition rates of $\mathrm{SiC}$ as a function of the total pressure.

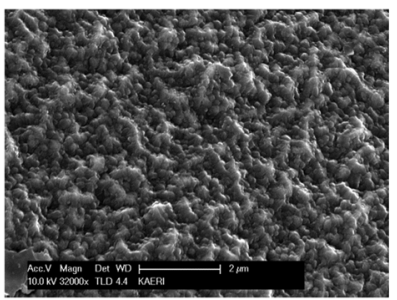

(a)

(c)

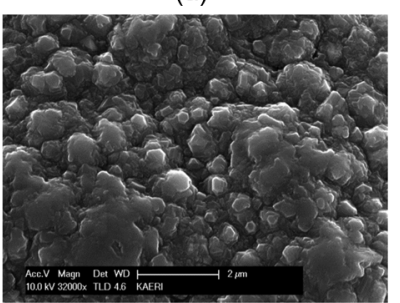

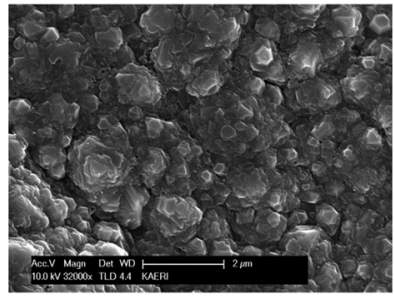

(b)

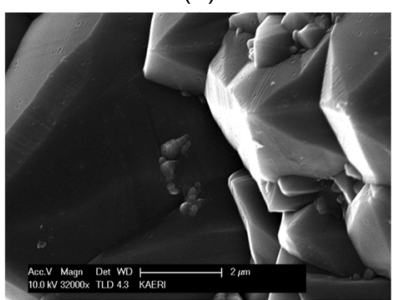

(d)
Fig. 5. Surface morphologies of $\mathrm{SiC}$ deposited at $1300^{\circ} \mathrm{C}$ under different total pressures: (a) $1.3 \mathrm{kPa}$, (b) $3.3 \mathrm{kPa}$, (c) $6.7 \mathrm{kPa}$, and (d) $10 \mathrm{kPa}$.

\section{2. 결정방위에 따른 경도 및 탄성계수의 변화}

Fig. 6 은 기체의 유량 및 증착 압력에 따른 $\mathrm{SiC}$ 증착층 의 $\mathrm{X}$ 선 회절피크의 변화를 보여 주고 있다. 모든 증착 압 력 조건에서 순수한 $\beta-\mathrm{SiC}$ 가 형성되어 있음을 알 수 있 다. 그러나, 증착 압력의 변화에 따라 (220)과 (311), 또는 (111) 피크가 강하게 나타나는 우선 배향면이 관찰이 된 다. 증착율이 낮은 $1.3 \mathrm{kPa}$ 의 압력에서는 (111) 우선 배향 면을 가지고, $3.3-10 \mathrm{kPa}$ 로 증착 압력이 증가함에 따라 (220)과 (311)에서 (111) 우선 배향성으로 변하고 있다.

우선배향성을 정량화하기 위해 $\mathrm{X}$ 선 회절피크의 상대강 도를 이용하여 TC(texture coefficient)를 구하였다. ${ }^{20)}$ 식 (2)은 Harris법에 의한 $\mathrm{TC}$ 를 산출하기 위한 식을 나타내 고 있다.

$$
T C=\frac{I_{i} / I_{0}}{(1 / n) \sum_{i=1}^{n}\left(I_{i} / I_{0}\right)}
$$

여기서, $I_{i} / I_{o}$ 는 이론강도 $\left(\mathrm{I}_{0}\right)$ 에 대한 $\mathrm{i}$ 번째 피크의 상대 강도 $\left(\mathrm{I}_{\mathrm{i}}\right)$ 비, $n$ 은 계산에 사용된 $\mathrm{X}$ 선 회절 피크의 수를 나 타낸다.

증착 압력에 따른 $\mathrm{SiC}$ 증착층의 (111), (220) 및 (311) 면 에 대한 $\mathrm{TC}$ 결과를 Table 1 에 나타내었다. $3.3 \mathrm{kPa}$ 에서 증 착된 $\mathrm{SiC}$ 는 이상적인 등방성의 $\mathrm{SiC}$ 보다 (220)과 (311) 우 선 배향성이 매우 크게 나타나며, $10 \mathrm{kPa}$ 에서 증착된 $\mathrm{SiC}$ 는 완전히 (111) 우선 배향성을 띄고 있음을 알 수 있다.

우선 배향성이 각각 다른 $3.3-10 \mathrm{kPa}$ 압력 조건에서 증 착된 $\mathrm{SiC}$ 를 이용하여, 나노인덴테이션 분석을 수행하였다. Fig. 7은 증착 압력이 3.3-10 kPa인 조건에서 증착된 $\mathrm{SiC}$ 층의 하중이 $80 \mathrm{~mA}$ 곡선을 보여 주고 있다. 최대 하중이 $80 \mathrm{mN}$ 에서, 변위량은 증착 압력이 높아 질수록 낮아지고 있다. 즉, 변위량의 감소는 압흔 면적이 줄어 들었음을 의

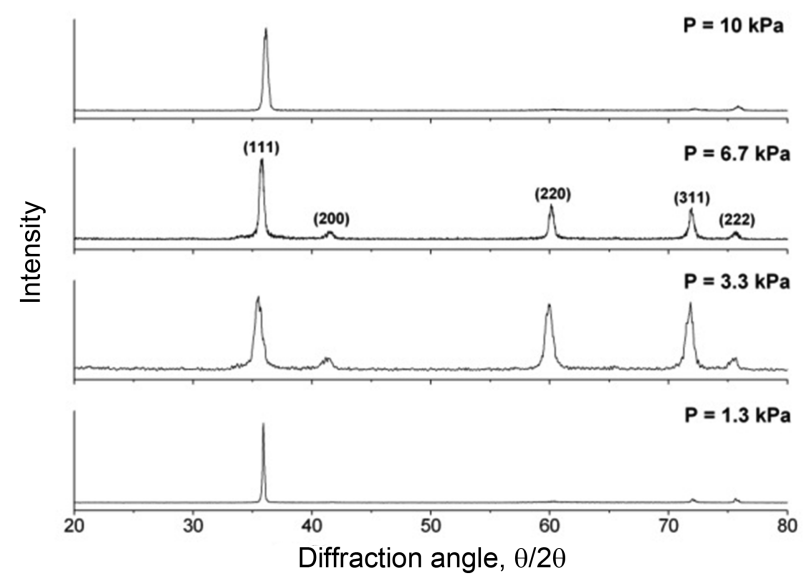

Fig. 6. X-ray diffraction patterns of as-deposited $\mathrm{SiC}$ as a function of the total pressure. 
Table 1. Relative Intensity of X-Ray Diffraction Peaks and Texture Coefficients for SiC Deposited in the Pressure Range of 3.3-10 kPa

\begin{tabular}{ccccccc}
\hline \multirow{2}{*}{$(\mathrm{hkl})$} & \multicolumn{2}{c}{$\mathrm{SiC}(\mathrm{P}=3.3 \mathrm{kPa})$} & \multicolumn{2}{c}{$\mathrm{SiC}(\mathrm{P}=6.7 \mathrm{kPa})$} & \multicolumn{2}{c}{$\mathrm{SiC}(\mathrm{P}=10 \mathrm{kPa})$} \\
\cline { 2 - 6 } & $\mathrm{I}_{\mathrm{i}} / \mathrm{I}_{0}$ & $\mathrm{TC}$ & $\mathrm{I}_{\mathrm{i}} / \mathrm{I}_{0}$ & $\mathrm{TC}$ & $\mathrm{I}_{\mathrm{i}} / \mathrm{I}_{0}$ & $\mathrm{~T}$ \\
\hline$(111)$ & 1 & 0.399 & 1 & 0.786 & 1 & 3 \\
$(220)$ & 2.56 & 1.02 & 1.22 & 0.960 & 0 & 0 \\
$(311)$ & 3.96 & 1.58 & 1.59 & 1.25 & 0 & 0 \\
\hline
\end{tabular}

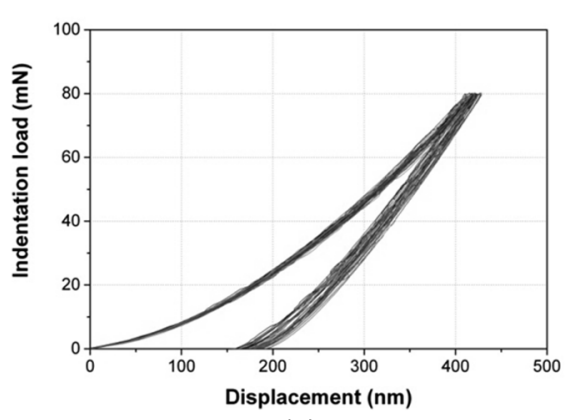

(a)

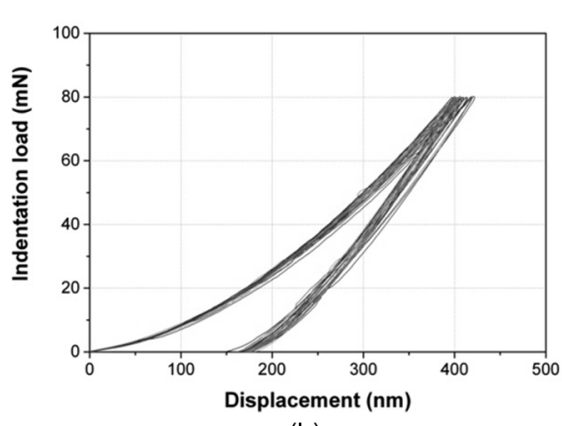

(b)

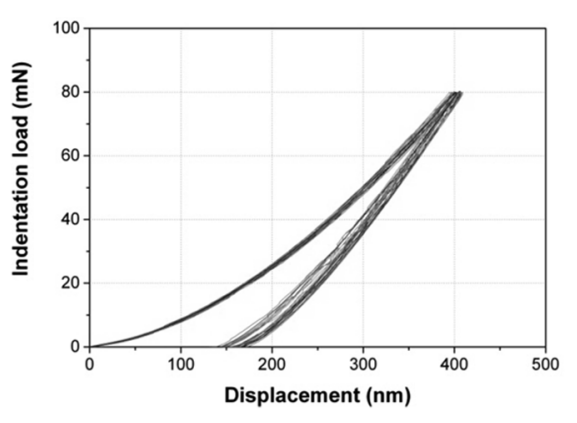

(c)

Fig. 7. Indentation load-displacement curves of $\mathrm{SiC}$ deposited at different total pressures: (a) $3.3 \mathrm{kPa}$, (b) $6.7 \mathrm{kPa}$, and (c) $10 \mathrm{kPa}$.

미하며, 증착 압력이 높아지면서 $\mathrm{SiC}$ 는 (111) 배향성이 커 지고, 이로 인하여 경도가 증가했기 때문이다.

Fig. 8은 (111)면에 대한 TC 값 변화와 이에 따른 경도 및 탄성계수 변화를 보여 주고 있다. 경도 및 탄성계수는 (111) 배향성이 커질수록 높아지는 것을 확인 할 수 있으 며, (220) 및 (311) 우선 배향성을 가지는 $3.3 \mathrm{kPa}$ 에서 증 착된 $\mathrm{SiC}$ 에 비해, 경도는 약 $15.7 \%$, 탄성계수는 약 $8.5 \%$ 증가했다. 경도 및 탄성계수는 재료의 밀도, 표면 상태, 집합조직 이방성, 결정립의 크기, 화학양론비 등 다양한 조건에 의해 영향을 받는 것으로 알려져 있다. ${ }^{21)}$ 본 연구 에서 증착된 $\mathrm{SiC}$ 의 경우 증착 온도 및 원료 기체비, 시편 연마 상태 등이 동일하기 때문에 밀도, 화학양론비, 표면 상태 등은 큰 영향을 미치지 않을 것으로 보이며,이방성 및 결정립의 크기가 주된 영향이 될 수 있다고 보여 진 다. 그러나, Fig. 5에서 보는 바와 같이 $10 \mathrm{kPa}$ 에서 증착된 (111) 우선 배향면을 가지고 있는 $\mathrm{SiC}$ 의 결정립의 크기가 가장 큼에도 불구하고 경도값이 높게 측정되었다. 이러한 경향은 다른 연구에서도 관찰이 되고 있으며, ${ }^{15)}$ 특히, Niihara, Harai는 이러한 결정립 방향에 따른 경도값의 차 이는 결정 성장 방위에 따른 $\beta-\mathrm{SiC}$ 의 주 슬립(primary slip)계의 차이 때문으로 분석하였고, 결정립 크기가 작은 (220) 우선 배향면을 가지는 $\mathrm{SiC}$ 에 비해, 결정립이 조대 한 (111) 우선 배향면의 $\mathrm{SiC}$ 의 경도가 더 높게 높게 측정 되었다. ${ }^{6,22)}$ 또한, 화학정량비를 가지는 $1400^{\circ} \mathrm{C}$ 에서 증착 된 $\mathrm{SiC}$ 에서도 결정 이방성의 영향이 관찰되고 있으며, (111) 우선 배향면을 가지는 $\mathrm{SiC}$ 가 (220) 우선 배향면을 가지는 $\mathrm{SiC}$ 보다 경도 값이 더 높게 나타났다. ${ }^{21)}$

Fig. 9은 (111) 우선 배향면을 가지는 $10 \mathrm{kPa}$ 에서 증착

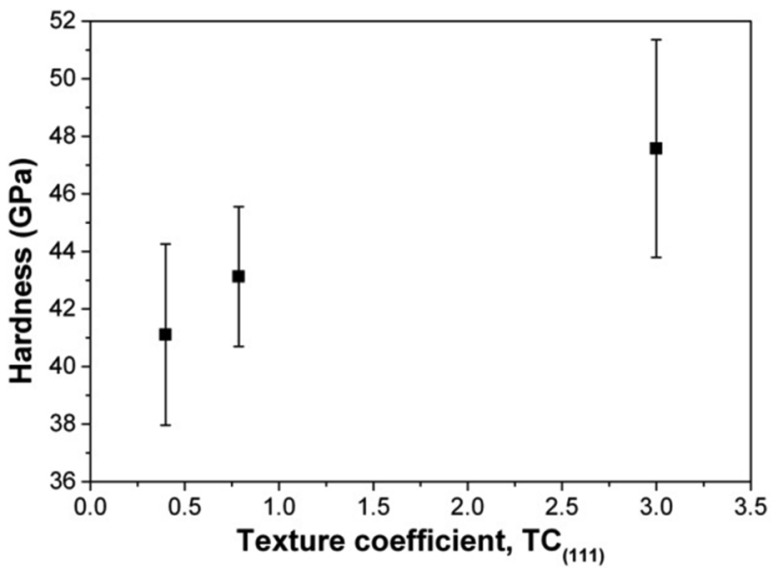

(a)

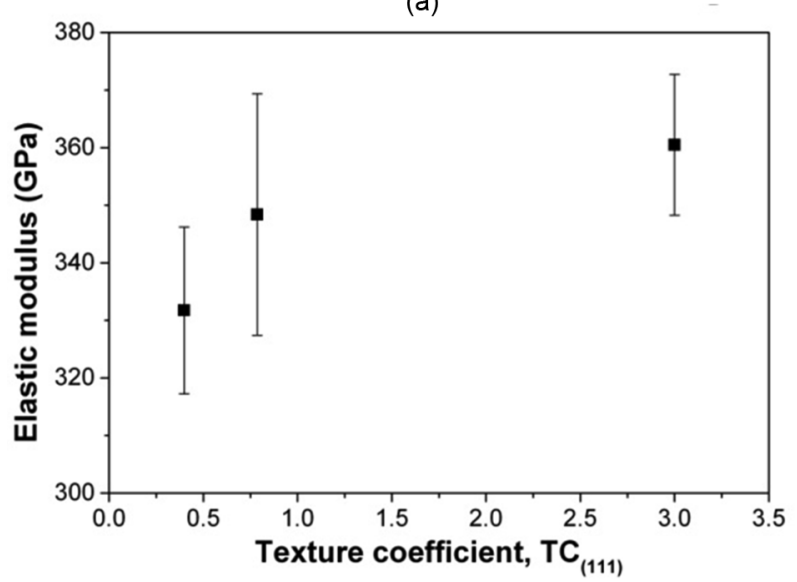

(b)

Fig. 8. Changes in hardness and elastic modulus values of $\mathrm{SiC}$ as a function of texture coefficient for the (111) plane: (a) hardness and (b) elastic modulus. 


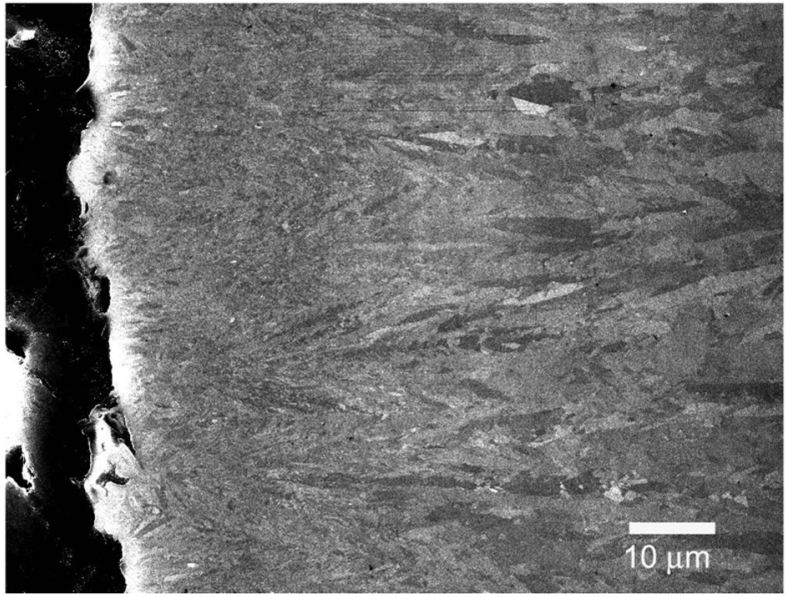

(a)

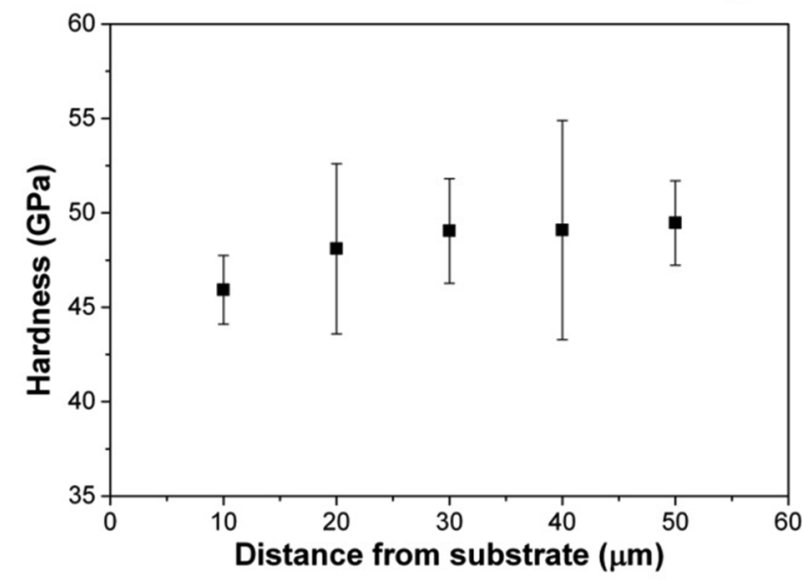

(b)

Fig. 9. (a) Cross-sectional microstructure and (b) hardness variations of $\mathrm{SiC}$ deposited at $10 \mathrm{kPa}$.

된 $\mathrm{SiC}$ 의 미세구조 및 흑연 기판으로부터 증착된 방향으 로의 거리에 따른 경도값의 변화를 보여 주고 있다. 흑연 기판에서 가까운 증착 초기의 미세구조는 columnar 구조 를 가지고 있지 않은 미세한 결정립의 $\mathrm{SiC}$ 가 성장하게 되 며 결정립의 우선 배향성이 없는 random한 집합구조를 갖는다. 반면, 증착층의 두께가 약 $20 \mu \mathrm{m}$ 이상 성장한 후 조대한 결정립을 가지는 전형적인 columnar 구조를 가지 며 (111) 면으로의 우선 배향성이 나타나게 된다. Fig. 9(b) 의 경도 측정 결과에서 증착 초기에 증착된 미세 결정립 의 $\mathrm{SiC}$ 에 비해 조대한 결정립 크기를 갖는 증착 후기 쪽 으로 갈수록 경도의 완만한 증가가 나타나는 것으로 보 아, 결정립의 크기보다는 결정의 이방성이 경도 및 탄성 계수에 더 큰 영향을 미치는 것으로 판단이 된다.

\section{4. 결 론}

$\mathrm{MTS}$ 를 이용한 $\mathrm{LPCVD}$ 법을 통해 $\beta-\mathrm{SiC}$ 를 증착 하였으 며, 증착조건에 따른 결정 이방성 및 이에 따른 기계적
특성 평가를 수행하였다. $1300^{\circ} \mathrm{C}$ 의 온도에서 증착된 $\mathrm{SiC}$ 의 경우 기체유량 $800-1600 \mathrm{sccm}$ 의 구간에서 증착율이 선형적으로 증가되었으며, 증착 압력이 증가함에 따라 증 착율이 증가 하다가 $3.3 \mathrm{kPa}$ 이상의 증착 압력에서는 증 착율의 변화가 관찰 되지 않았다. $3.3 \mathrm{kPa}$ 이상의 증착 압 력에서 $\mathrm{SiC}$ 의 우선 배향성은 (220)과 (311)에서 (111)로 변 했으며, (111) 우선 배향성이 증가함에 따라 경도 및 탄 성계수가 증가하였다. 반면, (220) 및 (311) 우선 배향성 을 가지는 $\mathrm{SiC}$ 의 경우 결정립의 크기가 작음에도 불구하 고 경도 및 탄성계수가 감소하는 경향을 보였으며, 이는 결정의 성장 방위의 변화에 기인한 것으로 판단이 된다.

\section{Acknowledgment}

본 연구는 교육과학기술부(MEST) 한국연구재단(NRF) 의 연구지원으로 수행되었으며, 이에 감사 드립니다 (No. 2012009818).

\section{REFERENCES}

1. Y. Katoh, L.L. Snead, T.D. Burchell, and W.E. Windes, Composite Technology Development Plan; Vol. 1, pp. 2031, ORNL/TM-2009/185, ORNL, Oak Ridge, 2010.

2. X.W. Zhou and C.H. Tang, "Current Status and Future Development of Coated Fuel Particles for High Temperature Gas-Cooled Reactors," Prog. Nucl. Energ., 53 182-88 (2011).

3. Y. Katoh, T. Nozawa, and L.L. Snead, "Mechanical Properties of Thin Pyrolytic Carbon Interphase SiC-Matrix Composites Reinforced with Near-Stoichiometric SiC Fibers," $J$. Am. Ceram. Soc., 88 [11] 3088-95 (2005).

4. T. Chuto, F. Nagase, and T. Fuketa, "High Temperature Oxidation of Nb-Containing Zr Alloy Cladding in LOCA Conditions," Nucl. Eng. Technol., 41 [2] 163-70 (2009).

5. H. Feinroth, M. Ales, E. Barringer, G. Kohse, D. Carpenter, and R. Jaramillo, "Mechanical Strength of CTP Triplex SiC Fuel Clad Tubes after Irradiation in MIT Research Reactor under PWR Coolant Conditions"; pp. 47-58, in Silicon Carbide and Carbon Composites, Vol. 30, Ceramic Engineering and Science Proceeding, Ed. by Y. Katoh and A. Cozzi, John Wiley \& Sons, New Jersey, 2009.

6. S. Sômiya and Y. Inomata, Silicon Carbide Ceramics; Vol. 1, pp. 77-98, Elsevier Science Publishers, New York, 1991.

7. J. H. Kim, H. K. Lee, J.-Y. Park, W.-J. Kim, and D.K. Kim, "Mechanical Properties of Chemical-Vapor-Deposited Silicon Carbide using a Nanoindentation Technique," J. Kor. Ceram. Soc., 45 [9] 518-23 (2008).

8. D. Lespiaux, F. Langlais, and R. Naslain, "Correlations between Gas Phase Supersaturation, Nucleation Process and Physico-Chemical Characteristics of Silicon Carbide Deposited from Si-C-H-Cl System on Silica Substrates," J. Mater. Sci., 30 1500-10 (1990).

9. J. Chin, P. K. Gantzel, and R. G. Hudson, "The Structure of 
Chemical Vapor Deposited Silicon Carbide," Thin Solid Films, 40 57-72 (1977).

10. F. Langlais and C. Prebende, "Physical and Chemical Kinetic Processes in the CVD of Silicon from $\mathrm{SiH}_{2} \mathrm{Cl}_{2} / \mathrm{H}_{2}$ Gaseous Mixtures in a Vertical Cylindrical Hot-Wall Reactor," J. Crystal Growth, 113 606-32 (1991).

11. F. Loumagne, F. Langlais, and R. Naslain, "Experimental Kinetic Study of the Chemical Vapor Deposition of SiCBased Ceramics from $\mathrm{CH}_{3} \mathrm{SiCl}_{3} / \mathrm{H}_{2}$ Gas Precursor," J. Crystal Growth, 155 198-204 (1995).

12. J.-S. Song, Y.-W. Kim, D.-J. Kim, D.-J. Choi, and J.-G. Lee, "Low Pressure Chemical Vapor Deposition of Silicon Carbide(in Korean)," J. Kor. Ceram, Soc., 31 [3] 257-64 (1994).

13. D.-J. Kim, D.-J. Choi, and Y.-W. Kim, "Effect of Reactant Depletion on the Microstructure and Preferred Orientation of Polycrystalline SiC Films by Chemical Vapor Deposition," Thin Solid Films, 266 192-97 (1995).

14. Y. long, A. Javed, Z. Chen, X. Xiong, and P. Xiao, "Deposition Rate, Texture, and Mechanical Properties of SiC Coatings Produced by Chemical Vapor Deposition at Different Temperatures," Int. J. Appl. Ceram. Technol., in press, 1-9 (2012).

15. H. K. Lee, J. H. Kim, and D. K. Kim, "Mechanical Properties of Chemical Vapor Deposited SiC Coating Layer(in Korean)," J. Kor. Ceram. Soc., 43 [8] 492-97 (2006).
16. M. Ganz, N. Dorval, M. Lefebvre, M. Péalat, F. Loumagne, and F. Langlais, "In Situ Optical Analysis of the Gas Phase during the Deposition of Silicon Carbide from Methyltrichlorosilane," J. Electrochem. Soc., 143 [5] 1654-61 (1996).

17. M.Y. Lee, J.Y. Park, W.-J. Kim, J.I. Kim, G.W. Hong, and S.G. Yoon, "Effect of Total Reaction Pressure on the Microstructure of the SiC deposited Layers by Low Pressure Chemical Vapor Deposition(in Korean)," J. Kor. Ceram. Soc., 38 [4] 388-92 (2001).

18. D. J. Cheng, W. J. Shyy, D. H. Kuo, and M. H. Hon, "Growth Characteristics of CVD Beta-Silicon Carbide," J. Electrochem. Soc., 134 [12] 3145-49 (1987).

19. J. H. Oh, C. H. Wang, D. J. Choi, and H. S. Song, "Fabrication of $\mathrm{CVD} \mathrm{SiC}$ Double Layer Structure from the Microstructural Change through Input Gas Ratio(in Korean)," J. Kor, Ceram, Soc., 36 [9] 937-45 (1999).

20. C.S. Barret, Structure of Metals; Vol. 2, pp. 170-195, McGrow-Hill, New York, 1952.

21. D.-J. Kim and D.-J. Choi, "Microhardness and Surface Roughness of Silicon Carbide by Chemical Vapour Deposition," J. Mater. Sci. Lett., 16 286-89 (1997).

22. K. Niihara, "Mechanical Properties of Chemically Vapor Deposited Nonoxide Ceramics," Am. Ceram. Soc. Bull., 63 [9] 1160-64 (1984). 